\title{
Syntheses, structures and properties of two coordination polymers of Cadmium(II) pseudohalide containing an in situ generated bidentate Schiff base: Control of dimensionality by varying pseudohalides
}

\author{
DIPU SUTRADHAR ${ }^{\mathrm{a}}$, HABIBAR CHOWDHURY ${ }^{\mathrm{b}}$, SUSHOVAN KONER $^{\mathrm{a}}$, \\ NIMAI CHANDRA SAHA ${ }^{\mathrm{c}, *}$ and BARINDRA KUMAR GHOSH ${ }^{\mathrm{a}, *}$ \\ ${ }^{a}$ Department of Chemistry, The University of Burdwan, Burdwan, West Bengal 713 104, India \\ ${ }^{b}$ Department of Chemistry, Kabi Nazrul College, Murarai, Birbhum, West Bengal 731 219, India \\ 'Vice-Chancellor's Research Group, Department of Zoology, The University of Burdwan, Burdwan, \\ West Bengal 713 104, India \\ E-mail: vcbunsaha@gmail.com; barin_1@yahoo.co.uk
}

MS received 30 June 2017; revised 22 September 2017; accepted 29 September 2017; published online 10 November 2017

\begin{abstract}
Two neutral coordination polymers of Cadmium(II) pseudohalide of the type $\left[\mathrm{Cd}(\mathrm{LL})\left(\mu_{1,5^{-}}\right.\right.$ $\left.\mathrm{dca})_{2}\right]_{\mathrm{n}}(\mathbf{1})$ and $\left[\mathrm{Cd}(\mathrm{LL})\left(\mu_{1,3}-\mathrm{NCS}\right)_{2}\right]_{\mathrm{n}}(2)(\mathrm{LL}=$ phenyl(pyridin-2-yl)methanimine and dca $=$ dicyanamide $)$ have been isolated using a 1:1:1:2 molar ratio of $\mathrm{CdCl}_{2} \cdot \mathrm{H}_{2} \mathrm{O}, 2$-aminopyridine (ap), 2-benzoylpyridine (bp) and $\mathrm{Na}(\mathrm{dca}) / \mathrm{NH}_{4} \mathrm{SCN}$ in alcoholic solvent at room temperature. X-ray structural study reveals that in the condensation reaction of ap and bp some degradation occurs in presence of the metal ion to afford an in situ generated bidentate Schiff base (LL) in the complexed form. Each Cadmium(II) center in both $\mathbf{1}$ and $\mathbf{2}$ adopts an octahedral geometry with a $\mathrm{CdN}_{6}$ chromophore in $\mathbf{1}$ and a $\mathrm{CdN}_{4} \mathrm{~S}_{2}$ chromophore in $\mathbf{2}$. In $\mathbf{1}$, each metal(II) center is connected to four other metal(II) centers through four different $\mu_{1,5}$-dca bridges affording a three-dimensional network structure, whereas each $\mathrm{Cd}$ (II) center in $\mathbf{2}$ is linked with neighbouring $\mathrm{Cd}$ (II) centers through bibridged end-to-end (EE) thiocyanates to form a non-ending linear 1D zig-zag chain. Further, in crystalline state 1D chains in $\mathbf{2}$ are stabilized through weak intermolecular C-H...S hydrogen bond interaction promoting 2D sheet structure. Thermally stable compounds 1 and $\mathbf{2}$ show intraligand ${ }^{1}\left(\pi-\pi^{*}\right)$ fluorescence in DMF solution at room temperature.
\end{abstract}

Keywords. Cadmium(II) coordination polymers; in situ generated Schiff base; dicyanamide/thiocyanate; $\mathrm{X}$-ray structures; luminescence.

\section{Introduction}

Construction of different coordination molecules and supramolecular entities ${ }^{1-3}$ through variation of ligand backbones and metal ion coordination environments has spawned immense interest in recent times. In this regard, Schiff base spacers and pseudohalide terminals/bridges are of great concern. Schiff bases ${ }^{4}$ are used as organic spacers because of their ease of preparation, structural variety, varied denticity and subtle steric and/or electronic effects controlling molecular and crystalline architectures. In contrast, in situ unusual ligand

\footnotetext{
*For correspondence
}

preparation ${ }^{5}$ in presence of different metal ions, which are very much efficient for the isolation of stable veritable metal-organic frameworks (MOFs) ${ }^{6}$ with exciting molecular properties, are rare. Dicyanamide (dca), a larger pseudohalide molecular ion-rod ${ }^{7,8}$ is under active consideration as bridging unit due to versatile coordination motifs leading to interesting extended molecular and crystalline architectures coupled with tunable properties in metal bound states. Ambidentate thiocyanate ${ }^{9,10}$ may act as terminal and/or bridging unit, and in the terminal mode it often participates in hydrogen bondings that influence supramolecular architectures. ${ }^{11}$ Self-assembly ${ }^{12}$ of the components is one of the efficient synthetic approaches to construct such entities 


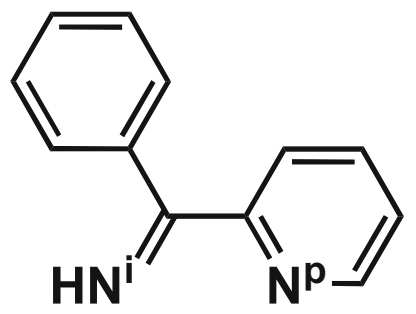

Scheme 1. Framework of LL with $\mathrm{N}^{\mathrm{i}}, \mathrm{N}^{\mathrm{P}}$ type backbone $\left(\mathrm{N}^{\mathrm{i}}=\right.$ imine $\mathrm{N} ; \mathrm{N}^{\mathrm{P}}=$ pyridine $\mathrm{N}$ ).

based on strong covalent bonds ${ }^{13}$ and multiple lateral weak non-covalent forces. ${ }^{14}$ Cadmium(II) compounds are of immense importance due to their structural varieties and electronic and optoelectronic properties. ${ }^{15-19}$ This prompted us to study Cadmium(II) chemistry with in situ generated Schiff base [phenyl(pyridin-2yl)methanimine (LL), Scheme 1] in conjunction with dca and thiocyanate as terminal and/or bridge unit. Successfully, we have isolated one 3D coordination polymer $\left[\mathrm{Cd}(\mathrm{LL})\left(\mu_{1,5}-\mathrm{dca}\right)_{2}\right]_{\mathrm{n}}$ (1) and one zigzag 1D coordination polymer $\left[\mathrm{Cd}(\mathrm{LL})\left(\mu_{1,3}-\mathrm{NCS}\right)_{2}\right]_{\mathrm{n}}(2)$ using a 1:1:1:2 molar ratio of $\mathrm{CdCl}_{2} \cdot 6 \mathrm{H}_{2} \mathrm{O}, 2$-aminopyridine (ap), 2-benzoylpyridine (bp) and $\mathrm{Na}(\mathrm{dca}) / \mathrm{NH}_{4} \mathrm{SCN}$ in alcoholic solvent at room temperature. The details of syntheses, spectroscopic results, X-ray structures and luminescence behavior of these compounds are described herein.

\section{Experimental}

\subsection{Materials}

High purity 2-aminopyridine (SRL, India), 2-benzoylpyridine (Lancaster, UK), Cadmuim(II) chloride monohydrate (SRL, India), sodium dicyanamide (Lancaster, UK) and ammonium thiocyanate (E. Merck, India) were purchased and used as received. The synthetic reactions and work-up were done in open air at room temperature. All other chemicals and solvents used were analytical reagent (AR) grade.

\subsection{Physical measurements}

Elemental analyses $(\mathrm{C}, \mathrm{H}$ and $\mathrm{N})$ were performed on a PerkinElmer $2400 \mathrm{CHNS} / \mathrm{O}$ elemental analyzer. IR spectra $(\mathrm{KBr}$ discs, $4000-400 \mathrm{~cm}^{-1}$ ) were recorded using a Perkin-Elmer FTIR model RX1 spectrometer. Thermal studies were made with a Perkin-Elmer Diamond TG/DTA analyzer heated from $30-800{ }^{\circ} \mathrm{C}$ under nitrogen atmosphere. Ground state absorption spectra were measured with a Jasco model V-530 UV-Vis

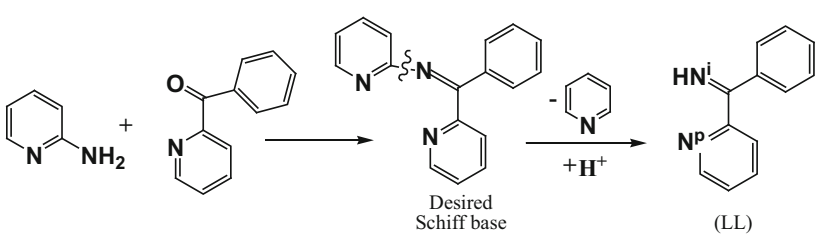

Scheme 2. Probable steps of the in situ reaction to afford LL.

spectrophotometer. Fluorescence measurements were done using a Fluorescence Spectrophotometer F-7000.

\subsection{Syntheses of the in situ ligand (LL) and complexes}

2.3a In situ generation of LL: Structural analysis of compounds $\mathbf{1}$ and $\mathbf{2}$ reveals the presence of a bidentate Schiff base (LL). It may be assumed that in the condensation reaction of 2-aminopyridine (ap) and 2-benzoylpyridine (bp), some degradation process ${ }^{5,20}$ occurs in presence of Cadmium(II) to result in this tailored Schiff base (LL). A possible path may be portrayed (Scheme 2) in which elimination of the pyridine ring followed by protonation presumably occurs.

$2.3 \mathrm{~b} \quad\left[C d(L L)\left(\mu_{1,5^{-}} d c a\right)_{2}\right]_{n}(1): \quad \mathrm{To} \mathrm{a} \mathrm{CdCl}_{2} \cdot \mathrm{H}_{2} \mathrm{O}(0.201$ $\mathrm{g}, 1 \mathrm{mmol})$ solution in $\mathrm{MeOH}(10 \mathrm{~mL}), 2$-aminopyridine $(0.094 \mathrm{~g}, 1 \mathrm{mmol})$ and 2-benzoyl pyridine $(0.183 \mathrm{~g}, 1$ $\mathrm{mmol})$ dissolved each in the same solvent $(10 \mathrm{~mL})$ were added drop wise. A solution of $\mathrm{Na}(\mathrm{dca})(0.178 \mathrm{~g}, 2 \mathrm{mmol})$ in the same solvent $(10 \mathrm{~mL})$ was added drop wise to this solution mixture. After filtration through a fine glass frit, the supernatant light reddish-orange solution was kept in air for slow evaporation. After three days, deposited yellow crystals of $\mathbf{1}$ were separated by filtration and dried in vacuo over silica gel indicator. Yield: $0.298 \mathrm{~g}(72 \%)$. Anal. Calc. for $\mathrm{C}_{16} \mathrm{H}_{10} \mathrm{~N}_{8} \mathrm{Cd}(\mathbf{1})$ : C, $45.0 ; \mathrm{H}, 2.4 ; \mathrm{N}, 26.3 \%$. Found: C, 44.8; H, 2.3; N, 26.2\%. IR $\left(\mathrm{KBr}, \mathrm{cm}^{-1}\right): v(\mathrm{C}=\mathrm{N}) 1639,1594 ; v_{\mathrm{as}}+v_{s}(\mathrm{C} \equiv \mathrm{N}) 2289$; $\nu_{\text {as }}(\mathrm{C} \equiv \mathrm{N}) 2239 ; v_{\mathrm{s}}(\mathrm{C} \equiv \mathrm{N}) 2167 ; v_{\mathrm{as}}(\mathrm{C}-\mathrm{N}) 1346 ; v_{\mathrm{s}}(\mathrm{C}-\mathrm{N})$ 952; $v(\mathrm{~N}-\mathrm{H})$ 3456. UV-Vis $\left(\lambda_{\max }, \mathrm{nm}\right): 272$.

$2.3 \mathrm{c} \quad\left[C d(L L)\left(\mu_{1,3}-N C S\right)_{2}\right]_{n}(2): \mathrm{CdCl}_{2} \cdot \mathrm{H}_{2} \mathrm{O}(0.201 \mathrm{~g}$, $1 \mathrm{mmol})$ dissolved in methanol $(10 \mathrm{~mL})$ was allowed to react with a solution mixture of 2-aminopyridine $(0.094 \mathrm{~g}, 1 \mathrm{mmol})$ and 2-benzoyl pyridine $(0.183 \mathrm{~g}, 1 \mathrm{mmol})$ in the same solvent $(15 \mathrm{~mL})$ followed by the addition of $\mathrm{NH}_{4} \mathrm{SCN}(0.152 \mathrm{~g}$, $2 \mathrm{mmol})$ in methanol $(10 \mathrm{~mL})$. The final solution was left undisturbed in open air for slow evaporation. The yellow microcrystals of $\mathbf{2}$ were collected as described in 1. Yield: $0.534 \mathrm{~g} \mathrm{(65 \% ).} \mathrm{Anal.} \mathrm{Calc.} \mathrm{for} \mathrm{C}_{28} \mathrm{H}_{20} \mathrm{~N}_{8} \mathrm{~S}_{4} \mathrm{Cd}_{2}$ (2): C, 41.0; H, 2.5; N, 13.6\%. Found: C, 40.8; H, 2.4; N, 13.5\%. IR (KBr, $\left.\mathrm{cm}^{-1}\right): v(\mathrm{C}=\mathrm{N}) 1631,1592 ; v(\mathrm{~N}=\mathrm{C}=\mathrm{S}) 2108 ; v(\mathrm{C}-\mathrm{S}) 770$; $\nu(\mathrm{N}-\mathrm{H}) 3450$. UV-Vis $\left(\lambda_{\max }, \mathrm{nm}\right): 267$.

\section{$2.4 \quad X$-ray crystallography}

Diffraction data of the single crystals of $\mathbf{1}$ and $\mathbf{2}$ were collected at 296 K on a Bruker SMART APEX II CCD area-detector 
Table 1. Crystallographic data and structure refinement in $\mathbf{1}$ and $\mathbf{2 .}$

\begin{tabular}{|c|c|c|}
\hline Compound & 1 & 2 \\
\hline Formula & $\mathrm{C}_{16} \mathrm{H}_{10} \mathrm{~N}_{8} \mathrm{Cd}$ & $\mathrm{C}_{28} \mathrm{H}_{20} \mathrm{~N}_{8} \mathrm{~S}_{4} \mathrm{Cd}_{2}$ \\
\hline Formula weight & 426.74 & 821.55 \\
\hline Crystal system & Orthorhombic & Triclinic \\
\hline Space group & $\mathrm{P} 2(1) 2(1) 2(1)$ & P1 \\
\hline$a(\AA)$ & $9.2634(17)$ & $8.7798(3)$ \\
\hline $\mathrm{b}(\AA)$ & $12.852(2)$ & $9.3608(3)$ \\
\hline$c(\AA)$ & $14.426(3)$ & $10.4566(3)$ \\
\hline$\alpha\left({ }^{\circ}\right)$ & 90.00 & $85.665(2)$ \\
\hline$\beta\left(^{\circ}\right)$ & 90.00 & 72.194(2) \\
\hline$\gamma\left({ }^{\circ}\right)$ & 90.00 & $73.465(2)$ \\
\hline$V\left(\AA^{3}\right)$ & $1717.5(6)$ & $784.32(4)$ \\
\hline$\lambda(\AA)$ & 0.71073 & 0.71073 \\
\hline$\rho_{\text {calcd }}\left(\mathrm{gm} \mathrm{cm}^{-3}\right)$ & 1.658 & 1.710 \\
\hline $\mathrm{Z}$ & 4 & 1 \\
\hline $\mathrm{T}(\mathrm{K})$ & 296(2) & $296(2)$ \\
\hline$\mu\left(\mathrm{mm}^{-1}\right)$ & 1.288 & 1.652 \\
\hline$F(000)$ & 848 & 397 \\
\hline Crystal size $\left(\mathrm{mm}^{3}\right)$ & $0.17 \times 0.15 \times 0.12$ & $0.15 \times 0.13 \times 0.11$ \\
\hline$\theta$ ranges $\left({ }^{\circ}\right)$ & 3.17 to 27.10 & 2.27 to 27.21 \\
\hline$h / k / l$ & $-11,11 /-11,16 /-16,18$ & $-11,11 /-11,11 /-13,13$ \\
\hline Reflections collected & 9557 & 11801 \\
\hline Data/restraints/parameters & $3662 / 0 / 226$ & $6044 / 0 / 379$ \\
\hline Goodness-of-fit on F2 & 0.978 & 0.847 \\
\hline Final $\mathrm{R}$ indices $[I>2 \sigma(I)]$ & 0.0459 & 0.0344 \\
\hline $\mathrm{R}$ indices (all data) & 0.0772 & 0.0475 \\
\hline Largest peak and hole $\left(\mathrm{e}^{-3}\right)$ & 0.462 and -0.537 & 0.604 and -0.599 \\
\hline
\end{tabular}

$\mathrm{R}=\Sigma|| \mathrm{Fo}|-| \mathrm{Fc}|| / \Sigma|\mathrm{Fo}|, \mathrm{wR}=\left[\Sigma \mathrm{w}\left(\mathrm{F}_{\mathrm{o}}^{2}-\mathrm{F}_{\mathrm{c}}^{2}\right)^{2} / \Sigma \mathrm{w}\left(\mathrm{F}_{\mathrm{o}}^{2}\right)^{2}\right]^{1 / 2}, \mathrm{calcd} \mathrm{w}=1 /\left[\sigma^{2}\left(\mathrm{~F}_{\mathrm{o}}^{2}\right)+(\mathrm{xP})^{2}+\mathrm{yP}\right] ; \mathrm{x}=0.0418($ for $\mathbf{1}), 0.1000$ (for 2), and $\mathrm{y}=0.0000$ (for 1), 0.0000 (for 2); where $\mathrm{P}=\left(\mathrm{F}_{\mathrm{o}}^{2}+2 \mathrm{~F}_{\mathrm{c}}^{2}\right) / 3$.

diffractometer using graphite monochromated Mo-K $\alpha$ radiation $(0.71073 \AA)$. The unit cell parameters were obtained from SAINT ${ }^{21}$ and absorption corrections were performed with SADABS. ${ }^{22}$ The structures were solved by direct methods and refined by full-matrix least-squares method based on $|\mathrm{F}|^{2}$ using SHELXL-97. All non-hydrogen atoms were refined with anisotropic displacement parameters. The $\mathrm{H}$ atoms were placed in calculated positions after checking their positions in the difference map. All calculations were carried out using SHELXL-97, ${ }^{23}$ SHELXTL, ${ }^{24}$ PLATON, ${ }^{25}$ and Mercury $3.3^{26}$ programs. A summary of the crystallographic data and structure determination parameters for both complexes is given in Table 1.

\section{Results and Discussion}

\subsection{Synthesis and formulation}

Two neutral hexacoordinated coordination polymers $\mathbf{1}$ and $\mathbf{2}$ of different dimensionalities were obtained through one-pot synthesis using 1:1:1:2 molar ratio of
Cadmium(II) chloride monohydrate, 2-aminopyridine, 2-benzoylpyridine and sodium dicyanamide/ammonium thiocyanate in methanolic solutions at room temperature. The reactions were reproducible, as were evident from repetitive microanalytical and spectral results. The reproducibility reflects an inherent tendency towards the formation of $\mathbf{1}$ and $\mathbf{2}$. The reactions are summarized in Eqs. 1 and 2:

$$
\begin{aligned}
& \mathrm{CdCl}_{2} \cdot \mathrm{H}_{2} \mathrm{O}+\mathrm{ap}+\mathrm{bp}+2 \mathrm{Na}(\mathrm{dca}) \\
& \stackrel{\mathrm{MeOH}}{\longrightarrow}\left[\mathrm{Cd}(\mathrm{LL})\left(\mu_{1,5}-\mathrm{dca}\right)_{2}\right]_{\mathrm{n}}+\text { Other products } \\
& \underset{298 \mathrm{~K}}{\mathrm{CdCl}_{2} \cdot \mathrm{H}_{2} \mathrm{O}+\mathrm{ap}+\mathrm{bp}+2 \mathrm{NH}_{4} \mathrm{SCN}} \\
& \underset{298 \mathrm{~K}}{\mathrm{MeOH}}\left[\mathrm{Cd}(\mathrm{LL})\left(\mu_{1,3}-\mathrm{NCS}\right)_{2}\right]_{\mathrm{n}}+\text { Other products }
\end{aligned}
$$

The moisture-insensitive compounds are stable over long periods of time in powdery or crystalline state and are soluble in dimethylformamide (DMF) and dimethylsulphoxide (DMSO). In DMF solutions, $\mathbf{1}$ and $\mathbf{2}$ behave as non-electrolyte as reflected from their low conductivity value $\left(\sim 5 \Omega^{-1} \mathrm{~cm}^{2} \mathrm{~mol}^{-1}\right)$. 


\subsection{Spectroscopic features}

In the IR spectrum, $v(\mathrm{C}=\mathrm{N})$ stretching frequencies of the metal-bound Schiff base ${ }^{27}$ in compounds $\mathbf{1}$ and $\mathbf{2}$ are observable at $\sim 1630$ and $\sim 1590 \mathrm{~cm}^{-1}$. Compound 1 shows strong $v_{s}(\mathrm{C} \equiv \mathrm{N})$ absorption at $2167 \mathrm{~cm}^{-1}$ and two weak to medium $v_{a s}(\mathrm{C} \equiv \mathrm{N})$ and $v_{a s}+v_{s}(\mathrm{C} \equiv \mathrm{N})$ absorptions at 2239 and $2289 \mathrm{~cm}^{-1}$, respectively; the shift of frequency values as compared to those of free dca $\left(2179,2232\right.$ and $\left.2286 \mathrm{~cm}^{-1}\right)$ is presumably due to bibridging $\left(\mu_{1,5}\right)$ coordination of dca. ${ }^{7}$ Bands corresponding to $v_{a s}(\mathrm{C}-\mathrm{N})$ and $v_{s}(\mathrm{C}-\mathrm{N})$ stretching vibrations of dca are found at $1346 \mathrm{~cm}^{-1}$ and at $952 \mathrm{~cm}^{-1}$, respectively. The $v(\mathrm{~N}=\mathrm{C}=\mathrm{S})$ stretching frequency is noticed at $2108 \mathrm{~cm}^{-1}$ and $v(\mathrm{C}-\mathrm{S})$ frequency is seen at $770 \mathrm{~cm}^{-1}$ for 2. A strong band at $\sim 3450 \mathrm{~cm}^{-1}$ assignable to $\nu(\mathrm{NH})$

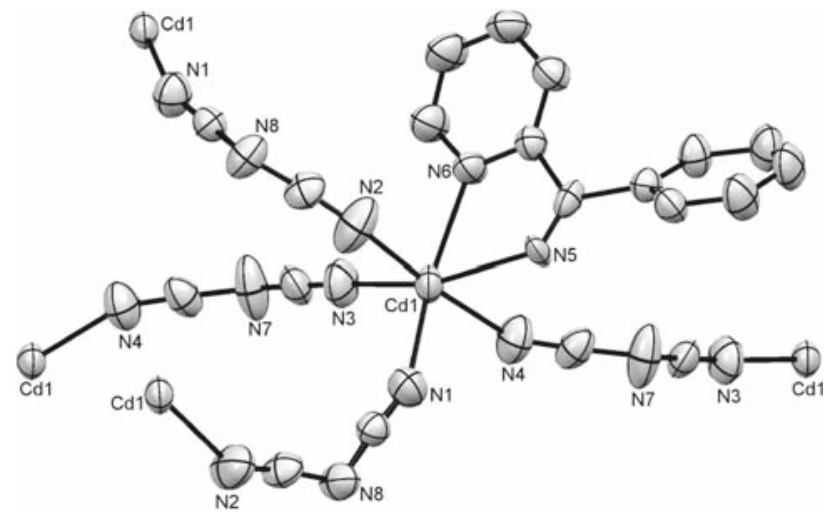

Figure 1. An ORTEP diagram of the fundamental coordination unit of 3D coordination polymer 1 with $40 \%$ probability level of the ellipsoid. stretching vibration of ligand (LL) is observed in both the compounds. The bands at 272 and $267 \mathrm{~nm}$ in UVVis spectra respectively in compounds $\mathbf{1}$ and $\mathbf{2}$ may be assigned to a ligand based charge transfer transition.

\subsection{Molecular and crystal structures}

3.3a $\left[C d(L L)\left(\mu_{1,5}-d c a\right)_{2}\right]_{n}(1):$ A perspective view of the fundamental unit with the atom labeling scheme and 3D network structure of the coordination polymer 1 are shown in Figures 1 and 2, respectively. Selected bond distances $(\AA)$ and bond angles $\left(^{\circ}\right)$ may be found in Table 2. Each Cadmium(II) center (Figure 1) in the polymeric framework adopts an octahedral geometry with a $\mathrm{CdN}_{6}$ chromophore ligated through $\mathrm{N}^{\mathrm{p}}(\mathrm{N} 6)$ and $\mathrm{N}^{\mathrm{i}}(\mathrm{N} 5)$ atoms $\left(\mathrm{N}^{\mathrm{p}}=\right.$ pyridine $\mathrm{N} ; \mathrm{N}^{\mathrm{i}}=$ imine $\left.\mathrm{N}\right)$ of bidentate Schiff base (LL) and four nitrile $\mathrm{N}$ atoms (N1, N2, N3 and N4) of four different dca units. The equatorial positions are occupied by the two nitrile $\mathrm{N}$ atoms (N1 and N3) of two different $\mu_{1,5}$-bridged dca units and two $\mathrm{N}$ atoms (N5 and N6) of the bidentate blocker and the other two nitrile $\mathrm{N}$ atoms (N2 and N4) of two different $\mu_{1,5}$-bridged dca units are placed at the axial positions. Distortion from the ideal octahedral geometry is due to the asymmetric nature of the bound bidentate Schiff base and the deviations of the refine angles $\left(90^{\circ} / 180^{\circ}\right)$ formed at the metal center. The degree of distortion from an ideal octahedral geometry is reflected in the equatorial $\left[68.17(18)^{\circ}-102.3(3)^{\circ}\right]$ and the axial $\left[160.5(2)^{\circ}-173.0(3)^{\circ}\right]$ bond angles. The $\mathrm{Cd} 1-\mathrm{N}_{\mathrm{dca}}$ distances lie in the range 2.238(7)-2.315(7) $\AA$, whereas Cd1-N(LL) distances are in the range of

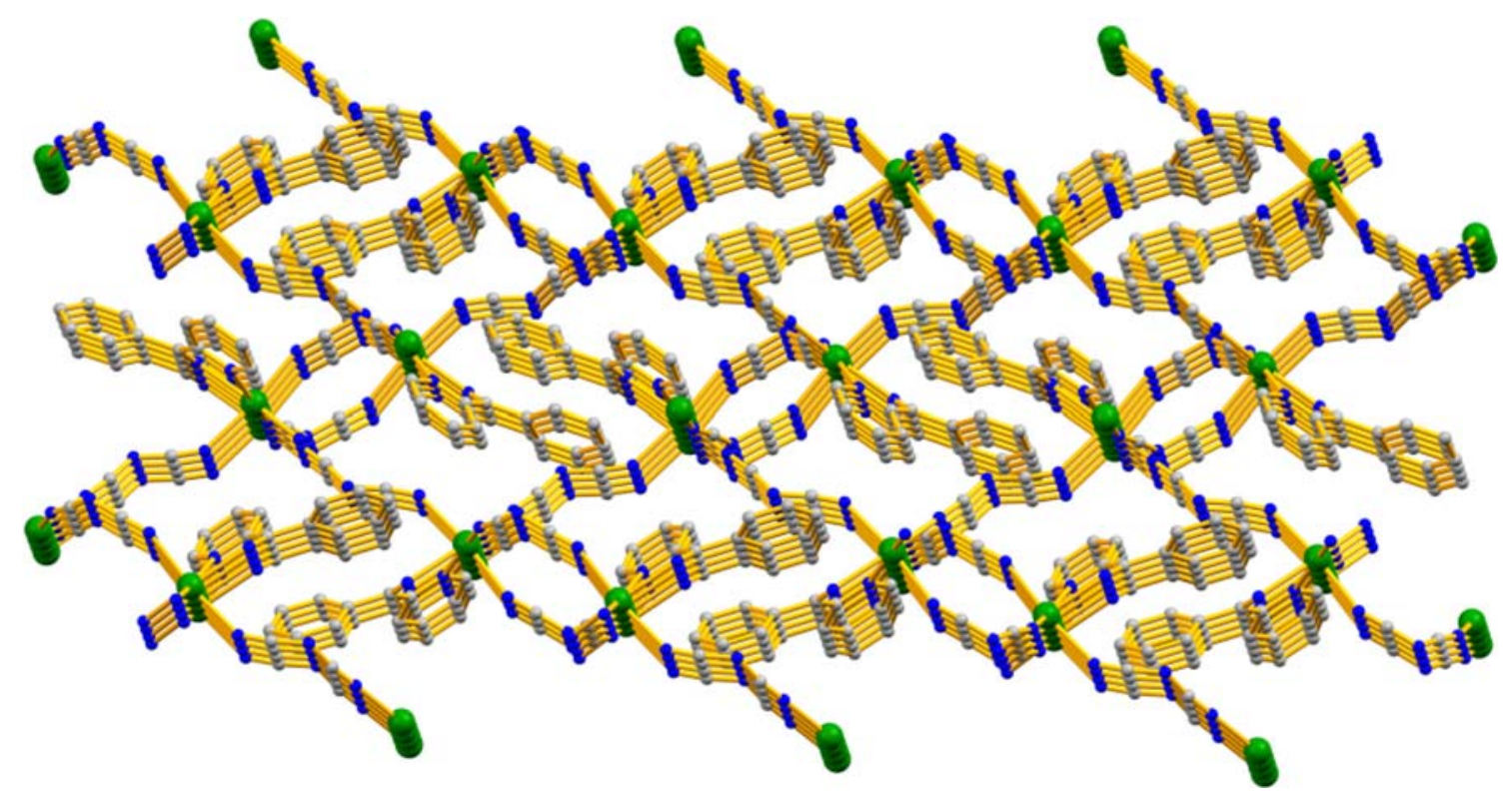

Figure 2. A Mercury view of 3D network structure in $\mathbf{1}$. 
Table 2. Selected bond distances $(\AA)$ and bond angles $\left(^{\circ}\right)$ for $\mathbf{1}$ and $\mathbf{2}$.

\begin{tabular}{lccc}
\hline \multicolumn{3}{l}{ Bond distance $(\AA)$} \\
\hline $\mathbf{1}$ & & & \\
Cd1-N1 & $2.238(7)$ & Cd1-N4 & $2.315(7)$ \\
Cd1-N2 & $2.295(7)$ & Cd1-N5 & $2.442(5)$ \\
Cd1-N3 & $2.270(7)$ & Cd1-N6 & $2.356(5)$ \\
$\mathbf{2}$ & & & \\
Cd1-N34 & $2.31(2)$ & Cd2-N33 & $2.224(16)$ \\
Cd1-N7 & $2.323(14)$ & Cd2-N37 & $2.329(13)$ \\
Cd1-N5 & $2.378(9)$ & Cd2-N4 & $2.389(12)$ \\
Cd1-N6 & $2.396(13)$ & Cd2-N3 & $2.434(13)$ \\
Cd1-S4 & $2.627(6)$ & Cd2-S2 & $2.621(5)$ \\
Cd1-S1 & $2.736(5)$ & Cd2-S3 & $2.745(6)$ \\
\hline
\end{tabular}

\section{Bond angle $\left({ }^{\circ}\right)$}

\begin{tabular}{lccc}
\hline 1 & & \\
N1 Cd1 N3 & $102.3(3)$ & N4 Cd1 N6 & $92.2(3)$ \\
N1 Cd1 N2 & $89.2(3)$ & N1 Cd1 N5 & $96.8(2)$ \\
N3 Cd1 N2 & $91.2(3)$ & N3 Cd1 N5 & $160.5(2)$ \\
N1 Cd1 N4 & $91.4(3)$ & N2 Cd1 N5 & $92.8(2)$ \\
N3 Cd1 N4 & $95.5(3)$ & N4 Cd1 N5 & $80.2(2)$ \\
N2 Cd1 N4 & $173.0(3)$ & N6-Cd1-N5 & $68.17(18)$ \\
N1 Cd1 N6 & $163.7(2)$ & C15 N7 C14 & $124.6(8)$ \\
N3 Cd1 N6 & $93.2(2)$ & C12 N8 C13 & $120.4(7)$ \\
N2 Cd1 N6 & $85.4(3)$ & & \\
2 & & & \\
N34 Cd1 N7 & $90.8(6)$ & N33 Cd2 N37 & $93.1(6)$ \\
N34 Cd1 N5 & $89.3(5)$ & N33 Cd2 N4 & $92.8(6)$ \\
N7 Cd1 N5 & $90.1(4)$ & N37 Cd2 N4 & $88.2(4)$ \\
N34 Cd1 N6 & $157.5(5)$ & N33 Cd2 N3 & $160.6(5)$ \\
N7 Cd1 N6 & $86.5(5)$ & N37 Cd2 N3 & $85.8(5)$ \\
N5 Cd1 N6 & $68.4(4)$ & N4 Cd2 N3 & $67.8(4)$ \\
N34 Cd1 S4 & $107.7(5)$ & N33 Cd2 S2 & $104.6(5)$ \\
N7 Cd1 S4 & $93.1(3)$ & N37 Cd2 S2 & $95.1(4)$ \\
N5 Cd1 S4 & $162.7(4)$ & N4 Cd2 S2 & $162.1(4)$ \\
N6 Cd1 S4 & $94.8(4)$ & N3 Cd2 S2 & $94.9(3)$ \\
N34 Cd1 S1 & $96.1(5)$ & N33 Cd2 S3 & $94.0(4)$ \\
N7 Cd1 S1 & $171.3(4)$ & N37 Cd2 S3 & $170.3(4)$ \\
N5 Cd1 S1 & $84.7(3)$ & N4 Cd2 S3 & $85.0(3)$ \\
N6 Cd1 S1 & $85.1(4)$ & N3 Cd2 S3 & $85.2(4)$ \\
S4 Cd1 S1 & $89.88(18)$ & S2 Cd2 S3 & $89.44(16)$ \\
N33 C1 S1 & $178.8(15)$ & N7 C44 S2 & $175.6(16)$ \\
N37 C47 S4 & $174.8(18)$ & N34 C3 S3 & $174.7(18)$ \\
\hline & & & \\
& & &
\end{tabular}

Symmetry code: ${ }^{\mathrm{i}}-\mathrm{x}, \mathrm{y}, 1 / 2-\mathrm{z}$; ii $3 / 2-\mathrm{x}, 1-\mathrm{y}, 1 / 2+\mathrm{z}$; ${ }^{i i i} 1-\mathrm{x},-1 / 2+\mathrm{y}, 1 / 2-\mathrm{z} ;{ }^{\text {iv }}-1 / 2+\mathrm{x}, 1 / 2-\mathrm{y},-\mathrm{z}$.

2.356(5)-2.442(5) $\AA$. The Cd ‥Cd separation across single $\mu_{1,5}$ dca ranges from 7.257 to $8.755 \AA$. The structural analyses reveal 1 to comprise of a $3 \mathrm{D}$ network structure through $\mu_{1,5}$-bridging motif of four dca units (Figure 2). All the Cadmium(II) atom lies in an inversion center, and is connected to four other neighboring Cadmium(II) centers through four different $\mu_{1,5}$-dca bridges.

3.3b $\quad\left[C d(L L)(N C S)_{2}\right]_{n}$ (2): An ORTEP diagram of the fundamental coordination unit of $\mathbf{2}$ with atom

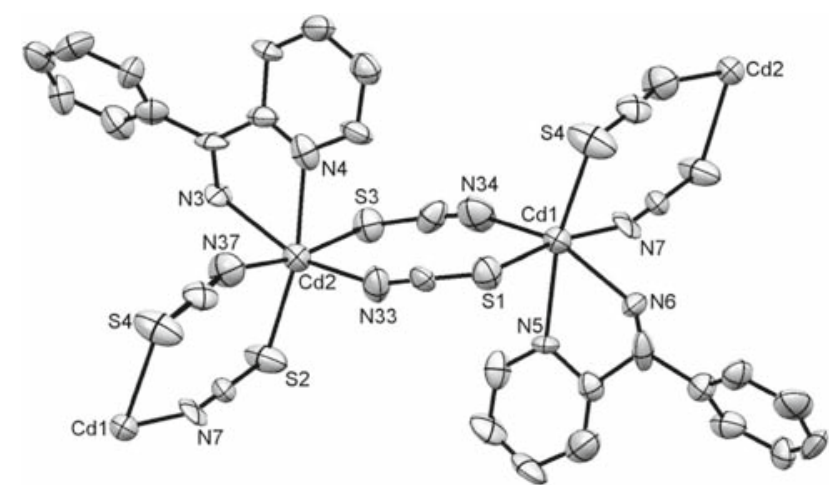

Figure 3. An ORTEP diagram of fundamental molecular unit of $\mathbf{2}$ with $40 \%$ probability level of the ellipsoid.

numbering scheme is shown in Figure 3. Selected bond distances $(\AA)$ and bond angles $\left(^{\circ}\right)$ are listed in Table 2 . Hydrogen bond interaction parameters are shown in Table 3. In compound $\mathbf{2}$, the adjacent Cadmium(II) centers are connected by the bibridged end-to-end thiocyanate units to form an extended structure with a zigzag 1-D chain (Figure 4). Each Cadmium(II) center in this chain is surrounded by a $\mathrm{CdN}_{4} \mathrm{~S}_{2}$ chromophore with a distorted octahedral geometry. The coordination sites of the metal ion are fulfilled by two $\mathrm{N}$ atoms $\left(\mathrm{N}^{\mathrm{i}}\right.$ and $\mathrm{N}^{\mathrm{p}}$ ) of chelated Schiff base (LL), two $\mathrm{N}$ atoms and two $\mathrm{S}$ atoms of bridging SCN ligand. The equatorial plane around $\mathrm{Cd} 1$ is made up with N5, N6 atoms of LL and N34, S4 atoms of SCN whereas N3, N4 atoms of LL and N33, S2 atoms of SCN comprise equatorial plane around $\mathrm{Cd} 2$ center. The axial sites are fulfilled by $\mathrm{S} 1, \mathrm{~N} 7$ atoms (in $\mathrm{Cd} 1$ ) and $\mathrm{S} 3, \mathrm{~N} 37$ atoms (in $\mathrm{Cd} 2$ ) of bridging $\mathrm{SCN}$ units. $\mathrm{Cd} 1$ and $\mathrm{Cd} 2$ deviate from the corresponding mean plane by $0.020 \AA$ and $0.047 \AA$, respectively. The degree of distortion from ideal octahedral geometry is seen in cisoid-[67.8(4)-107.7(5) $\left.{ }^{\circ}\right]$ and transoid-[157.5(5)-171.3(4) $\left.{ }^{\circ}\right]$ bond angles. Average $\mathrm{Cd}$...Cd separation through bibridged $\mathrm{SCN}$ ranges from 5.716 to $5.831 \AA$. The $1 \mathrm{D}$ chain in 2 self-assemble through cooperative intermolecular $\mathrm{C}-\mathrm{H} \cdots \mathrm{S}$ hydrogen bond interactions giving rise to a $2 \mathrm{D}$ supramolecular sheet structure along crystallographic $b c$ plane (Figure 5). The bridging sulfur atom (S3) is hydrogen bond acceptor whereas one $\mathrm{C}-\mathrm{H}(\mathrm{H} 7)$ of aromatic benzene ring is the donor $\left(\mathrm{C} 7-\mathrm{H} 7 \cdots \mathrm{S}^{\mathrm{v}} \mathrm{v}: 2.8700 \AA\right.$, $139.00^{\circ}$; symmetry code: $-1+\mathrm{x}, \mathrm{y}, \mathrm{z})$.

\subsection{Thermal studies}

Thermogravimetric analyses (TG) were made between 30 and $800{ }^{\circ} \mathrm{C}$ in a static atmosphere of nitrogen to examine thermal stabilities of the coordination polymers $\mathbf{1}$ and $\mathbf{2}$. The TG curve (Figure S1) of $\mathbf{1}$ indicates that it is 
stable up to $135^{\circ} \mathrm{C}$ at which temperature decomposition commences and takes place gradually in the temperature range $135-550{ }^{\circ} \mathrm{C}$ corresponding to the weight loss (observed, $73 \%$ and calculated, $74.8 \%$ ) of two dca units

Table 3. Non-covalent force parameters for $\mathbf{2}$.

Hydrogen bond interaction parameters $\left(\AA,^{\circ}\right)$

\begin{tabular}{lcccc}
$\mathrm{D}-\mathrm{H} \cdots \mathrm{A}$ & $\mathrm{D}-\mathrm{H}$ & $\mathrm{H} \cdots \mathrm{A}$ & $\mathrm{D} \cdots \mathrm{A}$ & $\mathrm{D}-\mathrm{H} \cdots \mathrm{A}$ \\
\hline $\mathrm{C} 7-\mathrm{H} 7 \cdots \mathrm{S} 3^{\mathrm{v}}$ & 0.9300 & 2.8700 & $3.619(19)$ & 139.00
\end{tabular}

Symmetry code: ${ }^{\mathrm{v}}-1+\mathrm{x}, \mathrm{y}, \mathrm{z}$. and one ligand (LL) unit per formula unit. The TG curve (Figure S2) of $\mathbf{2}$ shows that this compound is stable up to $180^{\circ} \mathrm{C}$ and its decomposition takes place gradually in the temperature range $180-660{ }^{\circ} \mathrm{C}$ corresponding to the weight loss (observed, 60\% and expected, 63.2\%) of two $\mathrm{NCS}^{-}$units and one ligand (LL) unit per formula unit.

\subsection{Fluorescence studies}

Light yellow-orange DMF solutions of compounds 1 and $\mathbf{2}$ showed strong absorption at 272 and 267

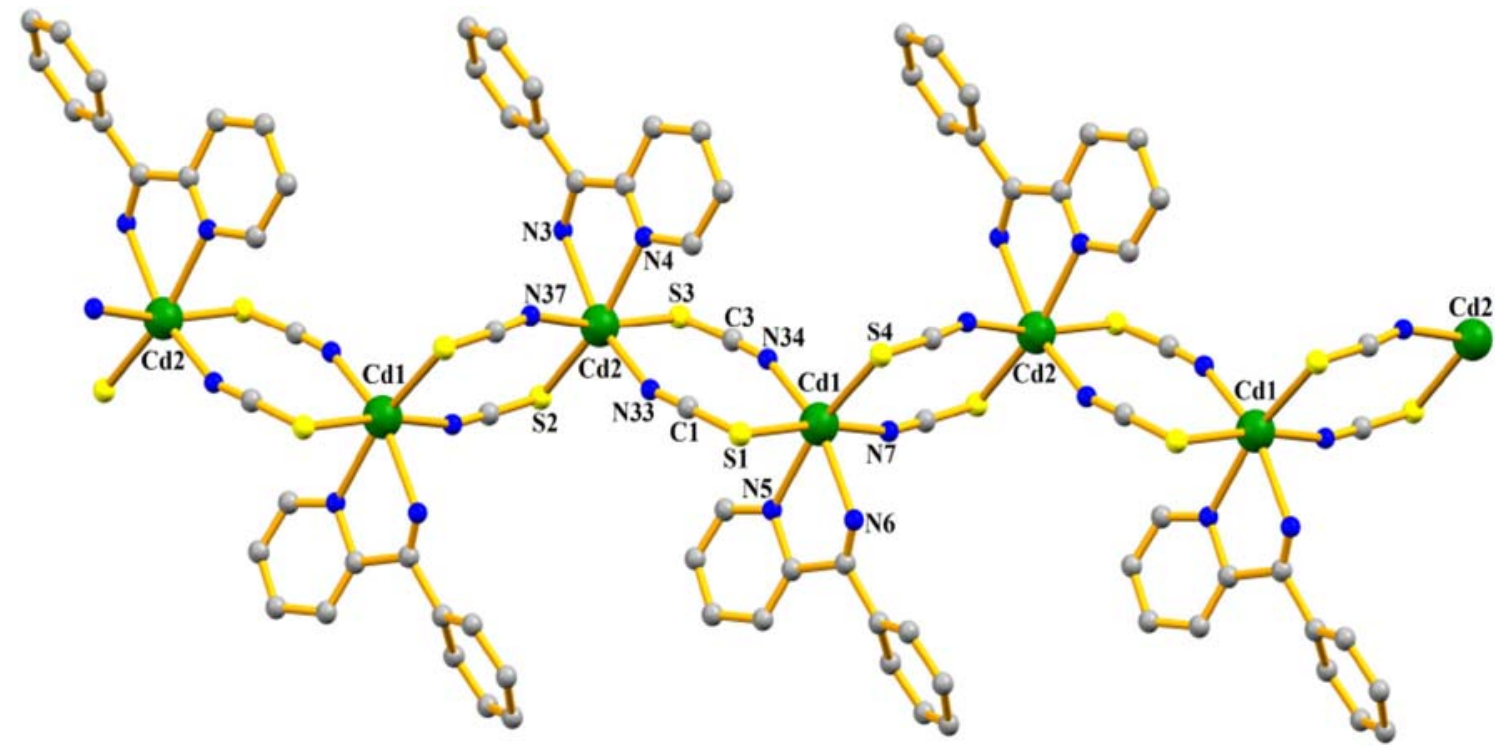

Figure 4. A segmented 1D zigzag chain in 2 along crystallographic $a b$-plane.

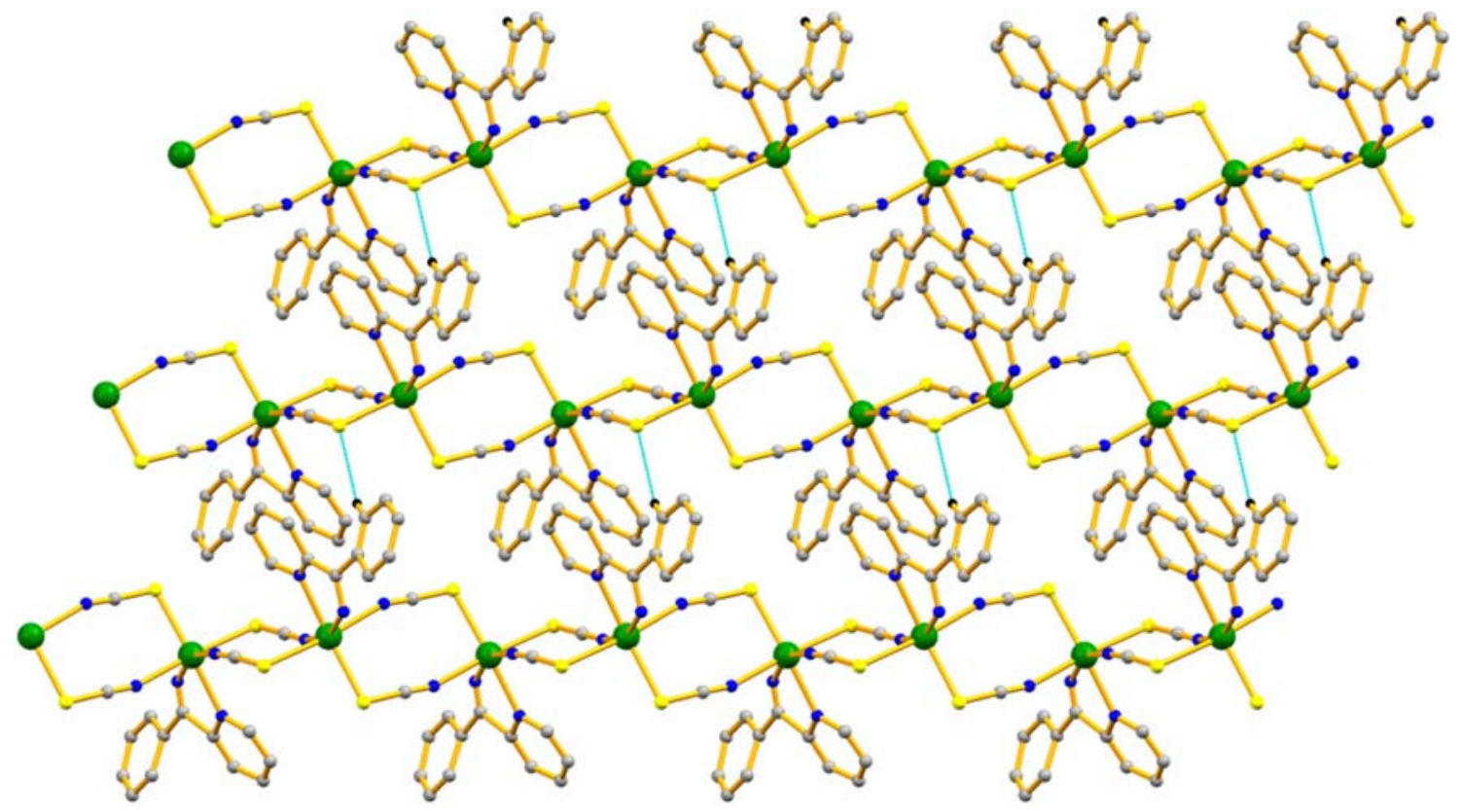

Figure 5. 2D sheet structure in 2 formed through $\mathrm{C}-\mathrm{H} \cdots \mathrm{S}$ hydrogen bonds. 


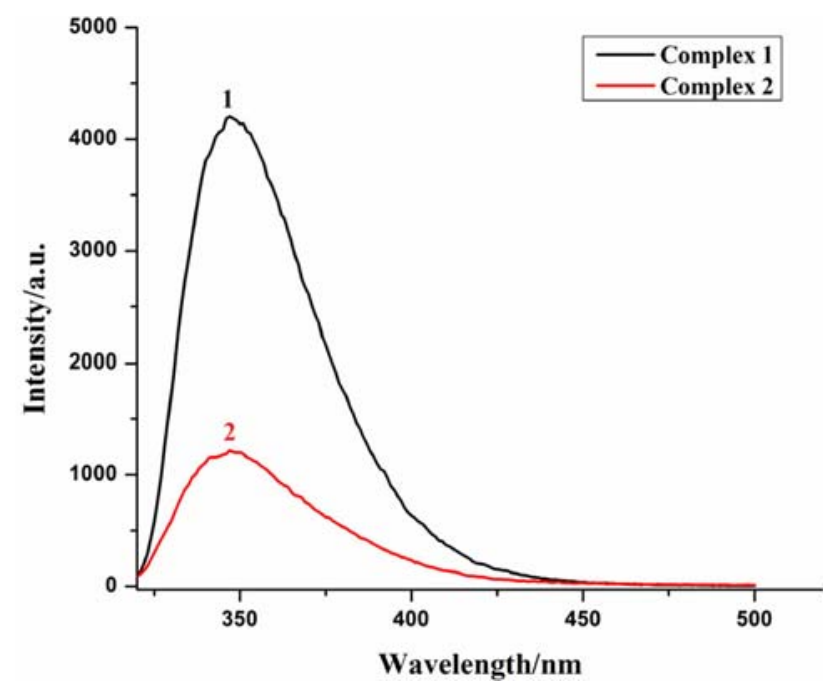

Figure 6. Fluorescence spectra of compounds $\mathbf{1}$ and $\mathbf{2}$ in DMF at $298 \mathrm{~K}$ (Excitation wavelength: $280 \mathrm{~nm}$ ).

$\mathrm{nm}$, respectively, presumably due to ligand-based transition. ${ }^{28}$ Upon photoexcitation at the corresponding absorption band in DMF solutions, 1 and 2 exhibit broad fluorescent emission centered at $347 \mathrm{~nm}$ due to the intraligand ${ }^{1}\left(\pi-\pi^{*}\right)$ transition (Figure 6$)$. The compound 1 showed more intense photoluminescence compared to compound $\mathbf{2}$ presumably due to greater conformational rigidity of the ligand (LL) upon coordination.

\section{Conclusions}

In summary, two uncharged coordination polymers of Cadmium(II) pseudohalide in combination with a bidentate Schiff base were isolated and characterized by X-ray crystallography. The compounds $\mathbf{1}$ and $\mathbf{2}$ have different molecular architectures of different dimensionalities just by incorporating varied pseudohalides. Weak intermolecular C-H...S hydrogen bond interactions in $\mathbf{2}$ are seen promoting the 1D chains to a 2D sheet structure. The coordination polymers are thermally stable, luminous materials. This work on such compounds illustrates the versatile approach towards construction of uncharged luminous metal-organic frameworks (MOFs), which have spawned great interest ${ }^{15-19,29}$ by different research groups towards isolation and application as electronic and optoelectronic materials with varied MOFs.

\section{Supplementary Information (SI)}

Crystallographic data for the structural analyses have been deposited with the Cambridge Crystallographic data center
No. 1452048 (1) and 1452049 (2). Copy of this information can be obtained, free of charge from The Director, CCDC, 12 Union Road, Cambridge, CB2 1EZ, UK (fax: +44 1223 336033; e-mail: deposit@ccdc.cam.ac.uk or http:// www.ccdc.cam.ac.uk). Thermal behavior of compounds $\mathbf{1}$ and 2 (Figures S1 and S2, respectively) are shown in Supplementray Information, available at www.ias.ac.in/chemsci.

\section{Acknowledgements}

Financial support from the CSIR [Scheme No. 01(2710)/13 /EMR-II dt 17-04-2013] and DST PURSE Phase 2 Programme [Sanction letter No. SR/PURSE Phase 2/34 dt 27-02-2017], New Delhi, India is gratefully acknowledged by BKG and NCS, respectively. HC thanks the UGC, ERO for financial assistance [Project No. F. No. PSW-20/13-14 (ERO)].

\section{References}

1. (a) Hong M -C and Chen L 2009 In Design and construction of coordination polymers (Hoboken, New Jersey: John Wiley \& Sons); (b) Zoworotko M J 2010 Design and Construction of Coordination Polymers J. Am. Chem. Soc. 132 7821; (c) Du M, Li C-P, Liu C-S and Fang S-M 2013 Design and construction of coordination polymers with mixed-ligand synthetic strategy Coord. Chem. Rev. 2571282

2. (a) Lehn J-M 1995 In Supramolecular chemistry: concepts and perspectives (Weinheim: VCH); (b) Steed J W and Atwood J L 2009 In Supramolecular chemistry $2^{\text {nd }}$ edn. (New York: Wiley); (c) Nabeshima T 2014 In Synergy in supramolecular chemistry (Boca Raton: CRC press, Taylor \& Francis)

3. (a) Yang L-Z, Fang R, Dou W, Kirillov A M, Xu C-L and Liu W-S 2015 Structural diversity in new coordination polymers modulated by semirigid ether-linked pyridinephthalate building block and ancillary ligands: syntheses, structures, and luminescence properties CrystEng Comm. 17 3117; (b) Huang F and Anslyn E V 2015 Introduction: Supramolecular Chemistry Chem. Rev. 1156999

4. (a) Vigato P A and Tamburini S 2008 Advances in acyclic compartmental ligands and related complexes Coord. Chem. Rev. 252 1871; (b) Karmakar T K, Chandra S K, Ribas J, Mostafa G, Lu T H and Ghosh B K 2002 Synthesis, structure and magnetism of a new dicubane-like ferromagnetic tetranuclear nickel cluster containing versatile azido-only bridges and a bis(bidentate) Schiff base blocker Chem. Commun. 2364; (c) Lin Z-J, Lu J, Hong M and Cao R 2014 Metal-organic frameworks based on flexible ligands (FL-MOFs): structures and applications Chem. Soc. Rev. 435867

5. (a) Zhao H, Qu Z-R, Ye H-Y and Xiong R-G 2008 In situ hydrothermal synthesis of tetrazole coordination polymers with interesting physical properties Chem. Soc. Rev. 37 84; (b) Satapathi S, Choubey S, Bhar K, Chattopadhyay S, Mitra P, Slawin A M Z and Ghosh B K 2012 A set of new coordination compounds of cadmium(II)/mercury(II) halides/pseudohalides containing polyamines: Syntheses involving in situ metal-ligand 
reactions, crystal structures and molecular properties Inorg. Chim. Acta 38437

6. (a) L R Macgillivray (Ed.) 2010 In Metal-organic frameworks: design and application (Hoboken, New Jersey: John Wiley \& Sons); (b) Coronado E and Espallargas G M 2013 Dynamic magnetic MOFs Chem. Soc. Rev. 42 1525; (c) Ricco R, Pfeiffer C, Sumida K, Sumby C J, Falcaro P, Furukawa S, Champness N R and Doonan C J 2016 Emerging applications of metal-organic frameworks CrystEngComm 186532

7. (a) Batten S R and Murray K S 2003 Structure and magnetism of coordination polymers containing dicyanamide and tricyanomethanide Coord. Chem. Rev. 246 103; (b) Li Q and Wang H-T 2014 A new threedimensional anionic cadmium(II) dicyanamide network Acta Cryst. C 70 1054; (c) Bhattacharyya A, Ghosh B N, Rissanen K and Chattopadhyay S 2016 Synthesis, characterization and self- assembly of three dicyanamide bridged polynuclear copper(II) complexes with $\mathrm{N}_{2} \mathrm{O}$ donor tridentate Schiff bases as blocking ligands Polyhedron 117 138; (d) Banerjee S, Halder S, Brandao P, Gomez Garcia C J, Benmasour S and Saha A 2017 Synthesis and characterization of a novel dicyanamidebridged $\mathrm{Co}$ (II) 1-D coordination polymer with a $\mathrm{N}_{4}$ Donor Schiff base ligand Inorg. Chim. Acta 46465

8. (a) Bhar K, Choubey S, Mitra P, Rosair G, Ribas J and Ghosh B K 2011 Syntheses, structures, luminescence and magnetic properties of two dinuclear $\mu_{1,5}$ dicyanamide bridged copper(II) complexes containing a tetradentate N-donor Schiff base J. Mol. Struct. 988 128; (c) Bhar K, Chattopadhyay S, Khan S, Krishnakumar R, Maji T K, Ribas J and Ghosh B K 2011 Syntheses, structures and magnetic properties of $\mu_{1,5}$ dicyanamide bridged coordination polymers of copper(II) and nickel(II) containing a tetradentate $\mathrm{N}$-donor Schiff base Inorg. Chim. Acta 370 492; (d) Kundu S, Roy S, Bhar K, Ghosh R, Lin C-H, Ribas J and Ghosh B K 2013 Syntheses, structures and magnetic properties of two one-dimensional coordination polymers of cobalt(II) and nickel(II) dicyanamide containing a tridentate N-donor Schiff base J. Mol. Struct. 1038 78; (e) Bhar K, Sutradhar D, Choubey S, Ghosh R, Lin C-H, Ribas J and Ghosh B K 2013 Hexa- and heptacoordinated manganese(II) dicyanamide complexes containing a tetradentate N-donor Schiff base: Syntheses, composition tailored architectures and magnetic properties $J$. Mol. Struct. 1051 107; (f) Roy S, Choubey S, Bhar K, Sikdar N, Costa J S, Mitra P and Ghosh B K 2015 Counter anion dependent gradual spin transition in a $1 \mathrm{D}$ cobalt(II) coordination polymer Dalton Trans. 447774

9. (a) A M Golub, H Kohler and V V Skopenko (Eds.) 1986 In Chemistry of pseudohalides (Amsterdam: Elsevier); (b) Malecki J G, Gron T and Duba H 2012 Structural, spectroscopic and magnetic properties of thiocyanate complexes of $\mathrm{Mn}(\mathrm{II}), \mathrm{Ni}(\mathrm{II})$ and $\mathrm{Cu}(\mathrm{II})$ with the 1-methylimidazole ligand Polyhedron 36 56; (c) Boeckmann J, Evers N and Nather C 2012 New nickel(II) thiocyanato coordination compounds: synthetic aspects, polymorphism, thermal reactivity and magnetic properties CrystEngComm 141094

10. (a) Ma Q, Zhu M, Yuan C, Feng S, Lu L and Wang Q 2010 A Molecular Helix: Self-Assembly of
Coordination Polymers from $\mathrm{d}^{10}$ Metal Ions and 1,10Phenanthroline-5,6-dione(pdon) with the Bridges of $\mathrm{SCN}^{-}$and $\mathrm{Cl}^{-}$Anions Cryst. Growth Des. 10 1706; (b) Li H-H, You Z-L, Zhang C-L, Yang M, Gao L-N and Wang L 2013 Zinc and thiocyanate-mediated oxazolidine ring formation in a trinuclear zinc(II) complex: Synthesis, structure, and properties Inorg. Chem. Comm. 29 118; (c) Machura B, Switlicka A, Mrozinski J, Kalinska B and Kruszynski R 2013 Structural diversity and magnetic properties of thiocyanate copper(II) complexes Polyhedron 521276

11. (a) Novoa J J, Braga D and Addadi L 2007 In Engineering of crystalline materials properties: state of the art in modeling, design and applications (Netherlands: Springer Science \& Business Media); (b) Samora P and Cacialli F 2014 In Functional supramolecular architectures: for organic electronics and nanotechnology (Weinheim: John Wiley \& Sons); (c) Zaworotko M J 2007 Molecules to Crystals, Crystals to Molecules and Back Again? Cryst. Growth Des. 7 4; (d) Zhang L, Zheng J-D, Chen Y-T, Zheng S-R, Fan J and Zhang W-G 2015 Syntheses, structures, and properties of nine $\mathrm{d}^{10}$ or p-block coordination polymers based on a ligand containing both terpyridyl and sulfo groups CrystEngComm 175538

12. (a) Chakrabarty R, Mukherjee P S and Stang P J 2011 Supramolecular Coordination: Self-Assembly of Finite Two- and Three-Dimensional Ensembles Chem. Rev. 111 6810; (b) Ward M D and Raithby P R 2013 Functional behaviour from controlled self-assembly: challenges and prospects Chem. Soc. Rev. 42 1619; (c) Carnes M E, Collins M S and Johnson D W 2014 Transmetalation of self-assembled, supramolecular complexes Chem. Soc. Rev. 431825

13. (a) Seidel S R and Stang P J 2002 High-Symmetry Coordination Cages via Self-Assembly Acc. Chem. Res. 35 972; (b) Steel P J 2005 Ligand Design in Multimetallic Architectures: Six Lessons Learned Acc. Chem. Res. 38 243; (c) Neidig M L, Clark D L and Martin R L 2013 Covalency in f-element complexes Coord. Chem. Rev. 257394

14. (a) Jeffrey G A 1997 In An introduction to hydrogen bonding (Oxford: Oxford University Press); (b) Nishio M, Hirota M and Umezawa Y 1998 In The $\mathrm{CH} / \pi$ interaction (New York: Wiley-VCH); (c) Tiekink E R T and Zukerman-Schpector J 2012 In The importance of pi-interactions in crystal engineering: frontiers in crystal engineering $1^{\text {st }}$ edn. (Chichester, UK: John Wiley \& Sons); (d) Reedijk J 2013 Coordination chemistry beyond Werner: interplay between hydrogen bonding and coordination Chem. Soc. Rev. 421776

15. (a) Chattopadhyay S, Bhar K, Das S, Khan S, Mitra P, Ribas J and Ghosh B K 2012 Heteronuclear complexes derived from the molecular ion $\left[\mathrm{Hg}(\mathrm{SCN})_{4}\right]^{2-}$ : Variance in bridging matrices, nuclearities and architectures with the change in complementary units Polyhedron 39 48; (b) Roy S, Choubey S, Khan K, Bhar K, Ribas J and Ghosh B K 2014 Synthesis, characterization and magnetic property of a succinate bridged 1D coordination polymer of cobalt(II) containing benzidine as end-capping ligand J. Mol. Struct. 1061 54; (c) Sutradhar D, Chowdhury H, Koner S, Roy S and Ghosh B K 2016 Two new 
hexacoordinated coordination polymers of cadmium(II) containing bridging units only: Syntheses, structures and molecular properties J. Chem. Sci. 1281377

16. (a) Ma K, Shi Q, Hu M, Cai X and Huang S 2009 Two Cd(II) and Ni(II) complexes constructed with dicyanamide and picolinate ligands Inorg. Chim. Acta 362 4926; (b) Liu L, Ding J, Huang C, Li M, Hou $\mathrm{H}$ and Fan Y 2014 Polynuclear $\mathrm{Cd}^{I I}$ Polymers: Crystal Structures, Topologies, and the Photodegradation for Organic Dye Contaminants Cryst. Growth Des. 14 3035; (c) Afkhami F A, Khandar A A, Mahmoudi G, Maniukiewicz W, Lipkowski J, White J M, Waterman R, Garcia-Granda S, Zangrando E, Bauzai A and Frontera A 2016 Synthesis, X-ray characterization, DFT calculations and Hirshfeld surface analysis of $\mathrm{Zn}$ (II) and $\mathrm{Cd}(\mathrm{II})$ complexes based on isonicotinoylhydrazone ligand CrystEngComm 184587

17. (a) Zhang H, Wang X, Zhang K and Teo B K 1999 Molecular and crystal engineering of a new class of inorganic cadmium-thiocyanate polymers with hostguest complexes as organic spacers, controllers, and templates Coord. Chem. Rev. 183 157; (b) Bushuev M B, Gatilov Y V, Krivopalov V P and Shkurko O P2015 Tetra- and polynuclear cadmium(II) complexes with 3,5-bis(pyrimidin-2-yl)-4H-1,2,4-triazol-4amine: Synthesis, polymorphism, lone pair- $\pi$ interactions and luminescence Inorg. Chim. Acta 425 182; (c) Cheng G-P, Xue L-W and Zhang C-X 2017 A Rarely Seen Phenolato and Azido-Bridged Polymeric Cadmium(II) Complex Derived from 2-Bromo-6-[(2isopropylaminoethylimino)methyl] phenol Acta Chim. Slov. 64261

18. (a) Special issue on Molecular materials in electronic and optoelectronic devices 1999 Acc. Chem. Res. 32 3; (b) Roundhill D M and Fackler Jr J P 2013 In Optoelectronic properties of inorganic compounds (New York: Springer Science \& Business Media)

19. (a) Balzani V, Credi A and Venturi M 2003 In Molecular devices and machines (Weinheim: Wiley-VCH); (b) Liao J, Blok S, Molen S J v d, Diefenbach S, Holleitner A W, Schonenberger C, Vladyka A and Calame M 2015 Ordered nanoparticle arrays interconnected by molecular linkers: electronic and optoelectronic properties Chem. Soc. Rev. 44999

20. (a) Roy S, Maji A K, Sutradhar D, Choubey S, Ghosh R and Ghosh B K 2015 Synthesis, molecular and crystalline architectures and properties of a cobalt (II) thiocyanate complex, containing an in situ generated didentate Schiff base J. Indian Chem. Soc. 92 1387; (b) Koner S, Chowdhury H, Ribas J and Ghosh B K 2016 A three-dimensional coordination polymer of cobalt(II)dicyanamide containing an in situ generated didentate Schiff base: Synthesis, structure and magnetic property J. Indian Chem. Soc. 931131
21. Sheldrick G M 1996 SAINT, V4: Software reference manual Siemens, SAINT v4: Software Reference Manual, Siemens Analytical X-Ray Systems, Madison, WI, USA

22. Sheldrick G M 1996 SADABS: Program for empirical absorption correction of area detector data (Germany: University of Gottingen)

23. (a) Herbst-Irmer R and Sheldrick G M 1998 Refinement of Twinned Structures with SHELXL97 Acta Crystallogr. 54 443; (b) Gruene T, Hahn H W, Luebben A V, Meilleur F and Sheldrick G M 2014 Refinement of macromolecular structures against neutron data with SHELXL2013 J. Appl. Crystallogr. 47 462

24. Sheldrick G M 2008 A short history of SHELX Acta Crystallogr. A64 112

25. Spek A L 2015 PLATON SQUEEZE: a tool for the calculation of the disordered solvent contribution to the calculated structure factors Acta Crystallogr. C71 9

26. Macrae C F, Edgington P R, McCabe P, Pidcock E, Shields G P, Taylor R, Towler M and van de Streek J 2006 Mercury: visualization and analysis of crystal structures J. Appl. Crystallogr. 39453

27. (a) Lever A B P 1984 In Inorganic electronic spectroscopy $2^{\text {nd }}$ edn. (New York: Elsevier); (b) Garcia Sole J, Bausa L E and Jaque D 2005 In An introduction to the optical spectroscopy of inorganic solids (New York: John Wiley \& Sons)

28. (a) Lakowicz J R 2006 In Principles of fluorescence spectroscopy $3^{\text {rd }}$ edn. (USA: Springer); (b) Petty M 2008 In Molecular electronics: from principles to practice (Chichester: Wiley); (c) Dutta B, Bag P, Florke $\mathrm{U}$ and Nag K 2005 Dinuclear Zinc(II) Complexes of Tetraiminodiphenol Macrocycles and Their Interactions with Carboxylate Anions and Amino Acids: Photoluminescence, Equilibria, and Structure Inorg. Chem. 44 147; (d) Chen W, Peng Q and Li Y 2008 Luminescent Bis-(8hydroxyquinoline) Cadmium Complex Nanorods Cryst. Growth Des. 8564

29. (a) Lin H, Lu H, Le M, Luan J, Wang X and Liu G Three 2 $\mathrm{D}$ copper(II)/cadmium(II) coordination polymers based on semi-rigid/flexible bis-pyridyl-bis-amide ligands and 5-aminoisophthalate: Syntheses, structures and properties, J. Chem. Sci. 127 1275; (b) Huang Y J, Pan Y R, Du G and Cao Y X 2016 Extended structures of two coordination polymers based on 1,10-phenanthroline derivatives: Preparation, structural characterization and properties J. Chem. Sci. 128 459; (c) Dong Y W, Wang P, Fan R Q, Chen W, Wang A N and Yang Y L 2017 Different conjugated system $\mathrm{Cd}(\mathrm{II}) / \mathrm{Hg}(\mathrm{II})$ Schiff base complexes: syntheses, supramolecular metalorganic frameworks, luminescent properties and DFT study J. Coord. Chem. 701953 